3

\title{
Flow Characterization of a Pulsating Heat Pipe through the Wavelet Analysis of Pressure Signals
}

\author{
Roberta Perna ${ }^{1}$, Mauro Abela ${ }^{1}$, Mauro Mameli ${ }^{1}$, Alessandro Mariotti ${ }^{2}$, Luca Pietrasanta ${ }^{3}$, \\ Marco Marengo ${ }^{3}$, Sauro Filippeschi ${ }^{1}$ \\ ${ }^{1}$ Department of Energy, Systems Land and Construction Engineering. University of Pisa, Largo L. Lazzarino, \\ Pisa, Italy. \\ ${ }^{2}$ Department of Civil and Industrial Engineering. University of Pisa, Via G, Caruso 8, 56122 Pisa, Italy. \\ ${ }^{3}$ Advanced Engineering Centre, School of Computing, Engineering and Mathematics. University of Brighton, \\ Lewes Road, BN2 4GJ Brighton, UK. \\ Corresponding author e-mail: c.robertaperna@gmail.com
}

\begin{abstract}
Pulsating Heat Pipes are two phase passive heat transfer devices characterized by a thermally induced two phase oscillating flow. The correct detection of the dominant frequencies of such oscillations is fundamental to fully characterize the device thermofluidic operation but the studies available in the literature are very heterogenous and results are often discordant. In this work, the concept of dominant frequency in Pulsating Heat Pipes is thoroughly discussed and defined analytically. The wavelet transform is used to characterize the fluid pressure signal in the frequency domain varying the heat power input at the evaporator and in the condenser zone of a full-scale Pulsating Heat Pipe tested in microgravity conditions. During the slug-plug flow regime, the dominant frequencies falls in the range $0.6-0.9 \mathrm{~Hz}$, showing an increasing trend with the heat load input. The Cross-Correlation reveals that the two signals at the evaporator and at the condenser are very similar. Finally, the instantaneous angle of phase is calculated and lies between 310 and $360 \mathrm{deg}$. This value can be physically interpreted as a repeatable time shift between the two signals that can be used to evaluate the flow local mean velocity $(0.09-$ $0.13 \mathrm{~m} / \mathrm{s}$ ) constituting a valuable alternative to the visualization techniques.
\end{abstract}

Keywords: Pulsating Heat Pipe, Frequency, Wavelet Cross Correlation, Flow velocity.

\begin{tabular}{|l|l|c|l|}
\hline \multicolumn{2}{|l|}{ Nomenclature } & & \\
\hline$C_{b}$ & bending pressure loss coefficients & $g$ & Gravitational acceleration $\left(\mathrm{m} / \mathrm{s}^{2}\right)$ \\
\hline$\psi$ & complex mother function & $f$ & Frequency $(\mathrm{Hz})$ \\
\hline$C_{\psi}$ & admissibility condition & $T$ & Temperature $\left({ }^{\circ} \mathrm{C}\right)$ \\
\hline$\hat{\psi}(\omega)$ & fourier transform & $P$ & Pressure $(\mathrm{Pa})$ \\
\hline$W_{x}$ & wavelet transform & $N_{W t}$ & number of samples \\
\hline$a$ & scale dilation parameter $(1 / \mathrm{Hz})$ & $N$ & Number of turns \\
\hline$\tau$ & translation parameter $(\mathrm{s})$ & $\dot{Q}$ & heat load input $(\mathrm{W})$ \\
\hline$P_{W_{x}}$ & wavelet power spectrum & $c$ & damping action \\
\hline$W_{x y}$ & wavelet cross scalogram & $m$ & Mass $(\mathrm{kg})$ \\
\hline$W L C C$ & wavelet local correlation coefficient & $\rho$ & Density $\left(\mathrm{kg} / \mathrm{m}^{3}\right)$ \\
\hline$\theta_{x-y}$ & instantaneous angle of phase $($ deg $)$ & $L$ & Length $(\mathrm{m})$ \\
\hline$C o W_{x y}$ & wavelet co-scalogram & $\mu$ & dynamic viscosity $(\mathrm{Pa} \mathrm{s})$ \\
\hline Subscripts & & \\
\hline$w$ & wall & $\mathrm{e}$ & evaporator \\
\hline $\mathrm{D}$ & dominant & $\mathrm{c}$ & condenser \\
\hline
\end{tabular}




\begin{tabular}{|l|l|c|l|}
\hline Max & maximum & $v$ & vapour \\
\hline C & characteristic & $l$ & liquid \\
\hline Ac & acquisition & $f$ & fluid \\
\hline An & analysis & & \\
\hline Abbreviations & & \\
\hline PHP & Pulsating Heat Pipe & WT & Wavelet Transform \\
\hline TS & ThermoSyphon & TC & Thermocouples \\
\hline FT & Fourier Transform & ESA & European Space Agency \\
\hline STFT & Short Time Fourier Transform & p & parabola \\
\hline HHT & Hilbert-Huang Transform & FR & Filling ratio \\
\hline TST & Time Strip Technique & & \\
\hline
\end{tabular}

\section{Introduction}

Thermally induced oscillations in two phase confined slug flows largely affect the operation of heat transfer devices such as micro-channel heat exchangers (MHE) and wickless heat pipes, also known as Pulsating Heat Pipes (PHPs). Regarding MHEs, these phenomena may lead to flow instabilities that are often detrimental for the device operation, causing a flow reversal to the inlet manifold [1] while, in PHPs, they constitute them vary basic working principle [2]. The frequency analysis of experimental data has been proved to be a promising tool to characterize such unstable behaviours in particular through the detection of dominant frequencies in the flow motion. The present work proposes to apply the wavelet transform to the fluid local pressure signal of a PHP in the evaporator and in the condenser zones, to rigorously define the concept of dominant and characteristic frequencies and link them to the device physical behaviour. Frequency analysis on PHP have already been performed in the literature but, as shown in the following state of the art, results are quite heterogeneous; Table 1 summarises, in chronological order, the most relevant works available in literature so far. They can be distinguished according to three main factors: i) the definition given for the dominant frequency of a PHP signal; ii) the type of time-frequency technique; iii) the type of experimental signal exploited for the analysis.

The obtained results show that the wavelet tool can detect the dominant frequencies in the system and used to extrapolate the mean fluid local velocity only by means of pressure signals, avoiding the complexity and cost of visualization techniques (i.e. transparent inserts and high speed cameras. 
Table 1. resume of the literature review

\begin{tabular}{|c|c|c|c|c|c|c|c|c|c|c|c|c|}
\hline \multirow[b]{2}{*}{ Authors name } & \multirow[b]{2}{*}{ Year } & \multicolumn{2}{|c|}{ Geometry } & \multirow{2}{*}{$\begin{array}{l}\text { I.D./O.D. } \\
\text { [mm] }\end{array}$} & \multirow[b]{2}{*}{$\begin{array}{c}\text { Working } \\
\text { fluid }\end{array}$} & \multirow[b]{2}{*}{ Signal } & \multirow[b]{2}{*}{ Section } & \multirow{2}{*}{$\begin{array}{l}\text { Type of } \\
\text { analysis }\end{array}$} & \multirow{2}{*}{\multicolumn{2}{|c|}{$\begin{array}{l}\text { Frequency } \\
{[\mathrm{Hz}]}\end{array}$}} & \multirow{2}{*}{$\begin{array}{c}\text { Vol. } \\
\text { F.R. } \\
\%\end{array}$} & \multirow{2}{*}{$\begin{array}{c}\text { Heat input } \\
\dot{Q}[\mathrm{~W}]\end{array}$} \\
\hline & & $\begin{array}{l}\text { Cross- } \\
\text { section }\end{array}$ & Turn & & & & & & & & & \\
\hline \multirow{2}{*}{$\begin{array}{c}\text { Jong-Soo et al. } \\
{[3]}\end{array}$} & \multirow{2}{*}{2003} & \multirow{2}{*}{ rectangular } & \multirow{2}{*}{10} & \multirow{2}{*}{$1.5 \times 1.5$} & \multirow{2}{*}{$\mathrm{R}-142 \mathrm{~b}^{*}$} & \multirow{2}{*}{$P_{f}$} & \multirow{2}{*}{ eva } & \multirow{2}{*}{ FT } & \multirow{2}{*}{\multicolumn{2}{|c|}{$\frac{1.22 ; 1.85}{1.71 ; 2}$}} & 40 & \multirow[b]{2}{*}{-} \\
\hline & & & & & & & & & & & 60 & \\
\hline \multirow{4}{*}{ Xu et al. [4] } & \multirow{4}{*}{2005} & \multirow{4}{*}{ tubular } & \multirow{4}{*}{3} & \multirow{4}{*}{$2 / 3$} & \multirow{4}{*}{$\mathrm{FC}-72 * *$} & \multirow{4}{*}{$T_{w}$} & \multirow{2}{*}{ eva } & \multirow{4}{*}{ FT } & & & & 12 \\
\hline & & & & & & & & & close to $\mathrm{Z}$ & $0.46 ; 0.9$ & 70 & 25.6 \\
\hline & & & & & & & & & & & 10 & 12 \\
\hline & & & & & & & cond & & close to & ; 0.46 & & 25.6 \\
\hline $\begin{array}{c}\text { Khandekar et } \\
\text { al. [5] }\end{array}$ & 2009 & tubular & 1 & $2 / 4$ & ethanol & $P_{f}$ & eva & FT & & & 60 & 20 \\
\hline 7 heos al 567 & & & & & & & & FT & & & & 210240 \\
\hline Zhao et al. [6] & 2011 & tubular & 6 & $1.65-3.18$ & water & $T_{w}$ & eva & WT & & & 49.2 & $210-240$ \\
\hline $\begin{array}{c}\text { Mameli et al. } \\
\text { [7] }\end{array}$ & 2012 & tubular & 2 & $2 / 4$ & ethanol & $P_{f}$ & adia & FT & & & - & $40-100$ \\
\hline & & & & & & & & & & 3.2 & 20 & \\
\hline & & & & & & & & & & 2.5 & 30 & \\
\hline & & & & & & & & & & 2.4 & 40 & \\
\hline Peng et al. & 2012 & tubular & 8 & 4 & ammonia & liavid slu & locity & HUT & $C_{b}=0$ & 2.3 & 50 & \\
\hline [8] & 2013 & tubular & 8 & 4 & & liquid slu & elocity & HHI & & 2.7 & 60 & - \\
\hline & & & & & & & & & & 2 & 70 & \\
\hline & & & & & acetone & & & & $C_{b}=0.2$ & 1.8 & 60 & \\
\hline & & & & & water & & & & $C_{b}=0.5$ & 1 & 60 & \\
\hline $\begin{array}{c}\text { Mameli et al. } \\
{[9]}\end{array}$ & 2014 & tubular & 2 & $2 / 4$ & ethanol & $P_{f}$ & adia & FT & & & 65 & $40-100$ \\
\hline Fairley et al. & 2015 & flat & 6 & 1.5 & water & $T_{w}$ & eva & $\begin{array}{l}\text { STFT energy } \\
\text { spectrum }\end{array}$ & & & 70 & $210-240$ \\
\hline [10] & & & & & & & & & & & & $210 ; 230$ \\
\hline
\end{tabular}




\begin{tabular}{|c|c|c|c|c|c|c|c|c|c|c|c|}
\hline & & & & & & & & $\begin{array}{l}\text { HHT energy } \\
\text { spectrum }\end{array}$ & 0.1 & & 240 \\
\hline & & & & & & & & $\begin{array}{c}\text { HHT } \\
\text { spectrum }\end{array}$ & $<0.2$ & & $210-240$ \\
\hline \multirow{2}{*}{$\begin{array}{l}\text { Karthikeyan et } \\
\text { al. [11] }\end{array}$} & \multirow[b]{2}{*}{2015} & \multirow[b]{2}{*}{ Tubular } & \multirow[b]{2}{*}{5} & \multirow[b]{2}{*}{$2.5 / 6$} & water & \multirow[b]{2}{*}{$T_{f}$} & \multirow[b]{2}{*}{$\begin{array}{l}\text { eva } \\
\text { cond }\end{array}$} & \multirow[b]{2}{*}{ FT } & \multirow[b]{2}{*}{-} & \multirow[b]{2}{*}{50} & \multirow[b]{2}{*}{50} \\
\hline & & & & & $\begin{array}{c}\mathrm{CuO} \\
\text { nanofluid }\end{array}$ & & & & & & \\
\hline \multirow{6}{*}{$\begin{array}{c}\text { Spinato et al. } \\
{[12]}\end{array}$} & \multirow{6}{*}{2015} & \multirow{6}{*}{ Flat } & \multirow{6}{*}{1} & \multirow{6}{*}{1} & \multirow{6}{*}{$\mathrm{R} 245 \mathrm{fa} * * *$} & \multirow{6}{*}{$T_{w}$} & \multirow{6}{*}{ eva } & \multirow{6}{*}{ TST } & - & \multirow{3}{*}{20} & 8 \\
\hline & & & & & & & & & 0.7 & & 22 \\
\hline & & & & & & & & & - & & 36 \\
\hline & & & & & & & & & 1.2 & \multirow{3}{*}{60} & $6-8$ \\
\hline & & & & & & & & & - & & $14-32$ \\
\hline & & & & & & & & & 1.2 & & 34 \\
\hline \multirow{4}{*}{$\begin{array}{c}\text { Monroe et al. } \\
{[13]}\end{array}$} & \multirow{4}{*}{2017} & \multirow{4}{*}{ tubular } & \multirow{4}{*}{4} & \multirow{4}{*}{$3.25 / 4.8$} & \multirow{4}{*}{ water } & \multirow{3}{*}{$T_{f}$} & \multirow{4}{*}{$\begin{array}{l}\text { eva } \\
\text { adia } \\
\text { cond }\end{array}$} & \multirow{4}{*}{ FT } & $\sim 2$ & & 60 \\
\hline & & & & & & & & & $\sim 3$ & 70 & 150 \\
\hline & & & & & & & & & $\sim 4$ & 10 & 275 \\
\hline & & & & & & $T_{w}$ & & & - & & \\
\hline & & & & & & & & & & & 14 \\
\hline $\begin{array}{c}\text { Chi et al. } \\
{[14]}\end{array}$ & 2018 & tubular & 15 & $1 / 2$ & ethanol & $T_{w}$ & eva & FT & $0-0.1$ & $\begin{array}{c}6.7- \\
40\end{array}$ & 20 \\
\hline & & & & & & & & & & & 25 \\
\hline & & & & & & & & & - & & 74.4 \\
\hline & & & & & & & & & & & 118.3 \\
\hline Ishii et al. & 2019 & Flat & 12 & & water & $T$ & eyo & ET & $<3$ & 50 & 172 \\
\hline [15] & 2013 & 1 iat & & & water & $I_{f}$ & via & & & (5) & 238 \\
\hline & & & & & & & & & 2 & & 316 \\
\hline & & & & & & & & & 2 & & 405 \\
\hline $\begin{array}{c}\text { Takawale et al. } \\
{[16]}\end{array}$ & 2019 & Tubular & 17 & $1 / 2$ & ethanol & $P_{f}$ & cond & FT & - & 60 & $64-112$ \\
\hline
\end{tabular}

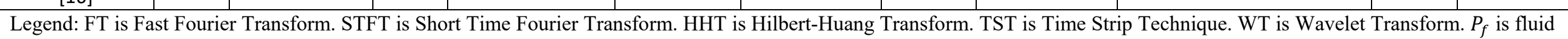
pressure. $T_{f}$ is fluid temperature. $T_{w}$ is wall temperature. $C_{b}$ is bending pressure loss coefficients. ${ }^{*}$ Chlorodifluoroethane ** Perfluorohexane. $* * *$ Pentafluoropropane. 


\subsection{The dominant frequency}

Only a few authors provided a definition of dominant frequency so far in the literature. Xu et al. [4] are among the first to introduce the time-frequency analysis as a tool for the PHPs thermofluidic investigation and they define the dominant frequency as a peak of energy in the Power Spectrum. Their work exploits the Fourier Transform (FT) analysis on three wall temperatures signals, in the evaporator and the condenser section at different heat loads. At 12 $\mathrm{W}$, the dominant frequency values $(0.1 \mathrm{~Hz})$ are much smaller than those obtained for $25.6 \mathrm{~W}$ $(0.46-0.9 \mathrm{~Hz})$. Additionally, Karthikeyan et al. [11] applied the FT on the temperature signal at different working fluid, deionized water and $\mathrm{CuO}$ nanofluid. The frequency wasn't found by means the time-frequency technique, and the authors concluded that the results depend on the chaotic nature of the PHP oscillation. In Jong-Soo et al. [3], the Fourier Transform is achieved on the pressure signal and the dominant frequencies were determined to be $1.22 \mathrm{~Hz}$ and 1.85 $\mathrm{Hz}$ (at 40 vol.\%) and $1.71 \mathrm{~Hz}$ and $2 \mathrm{~Hz}$ (at 60 vol.\%). Mameli et al. [7][9]performed the FT analysis on the pressure signal at different heat input levels without recognizing any peak in the power spectra and thus opening the discussion on whether the FT would be the most suitable tool for the frequency detection. Also, in Takawalea et al. [16], the FT is applied on the pressure signals, but the dominant frequencies cannot be found too. Despite the FT analysis has been exploited more extensively with respect to other techniques, it is intrinsically not able to detect the time range where the dominant frequencies occur, so the analysis is often performed on very large amount of data and it often provides noisy outputs where peaks are hardly recognizable. In this vein, Fairley et al. [10] describe the presence of energy peaks in the Power Spectrum as occurrence of intermittent high-energy oscillations in the PHP evaporator temperature signal. In their study, the Short-Time Fourier Transform (STFT) and Hilbert-Huang Transform (HHT) analyses are performed on the wall temperature and at different heat loads. The Hilbert-Huang energy spectrum shows intermittent oscillations at frequencies between 0.2 and $0.4 \mathrm{~Hz}$. In the Hilbert-Huang marginal spectra, the intermittent high-energy peaks fall in the range 0.02-0.2 Hz. The power spectrum of temperature signal tends to decrease when the heat input increases, in accordance with Ishii et al. [15] and Peng et al. [8] but in opposition with Spinato et al. [12] and Monroe et al. [13]. The results of the STFT are like those obtained with HHT, but the HHT's sharper time and frequency resolution makes some features of the energy spectra more evident. Overall, works derive a definition of dominant frequency only from a visual interpretation of graphical results.

In Spinato et al. [12], the Time Strip Technique (TST) [12], a novel synchronized thermal and visual investigation technique, is used to assess the thermal and hydrodynamic behaviours in a single loop PHP. The 3D frequency spectra are computed for the local evaporator and condenser wall temperatures, as well as for the time-strip (or interval in the time domain) intensity at the same locations. Dominant frequencies are $0.6 \mathrm{~Hz}$ for $\mathrm{FR}=20 \%$ and $1,2 \mathrm{~Hz}$ for $\mathrm{FR}=60 \%$. The condenser signal results are almost absent, compared to the result obtained at the evaporator. In the present work, the Wavelet Transform (WT) is chosen because it can overcome the limits of FT and STFT. In this sense, the WT is a powerful tool with a good capacity for time-frequency localizations and multiresolution representations, giving the possibility to "locate" the eventual 
dominant frequency in time [17] [18]. A rigorous and comparable way to define the dominant frequency of a PHP starting from the wavelet analysis of the fluid pressure signal is proposed in section 3.2.

\subsection{Choice of the PHP signals}

All the techniques mentioned in the previous section are applied to different types of thermofluidic signals. Much research analyses the PHP pseudo-steady state, and the most common choice for the signal is the wall temperature. Zhao et al. [6] apply the FT and the WT to the wall temperature signal but no dominant frequency is identified. Chi et al. [14] use the FT on the wall temperature signal too and find frequencies up to $0.1 \mathrm{~Hz}$. Monroe et al. [13] are among the first that compare the results obtained by the wall temperature signal analysis with those obtained by the fluid temperature signal analysis. In their work, two thermocouples (TCs) are placed inside (fluid) and on top (wall) of an operating PHP. The results show that the frequencies of the fluid temperature fall in the range from 2 to $4 \mathrm{~Hz}$, while no frequencies are detected by the wall temperature analysis, due to the thermal inertia of the tube. The FT is also applied by Ishii et al. [15] on the fluid temperature signal. For heat loads of 74.4 to $112 \mathrm{~W}$, there is not any visible peak in the power spectrum, while for $316 \mathrm{~W}$ and $415 \mathrm{~W}$ the peaks are identified around 2 and $3 \mathrm{~Hz}$. In addition to the signals recorded during the experimental tests, some authors apply the frequency analysis to the numerical output of their models but this may be misleading if the model is not validated, at least partially, against experimental data. Peng at al. [8], for example, present a nonlinear thermomechanical finite-element model of PHP that aims at simulating the slug oscillation, and then calculate the time-varying spatial distributions (HHT) of the slugs velocity by varying different parameters. If the bending pressure loss coefficients $C_{b}$ and the heat input increase, the frequencies decrease and they fall in the range 1-3.2 Hz. Finally, some authors, apply the Fourier Transform on the fluid pressure signal (e.g. [7], [9]). Among these works Khandekar et al. [5] focus on a steady state and transition state of operation PHP. The frequency falls in the range from 0.1 to $3 \mathrm{~Hz}$. The choice of the fluid pressure signal brings substantial advantages with respect to the others signals (wall and fluid temperatures) because it is directly related to the fluid motion, it is not affected by the probe thermal inertia, thus, it allows to acquire data at a very high sampling rates. As shown in the next sections, the wavelet analysis presented here is performed at first on all the three signals (wall temperature, fluid temperature and fluid pressure) to give proof of the above advantages, then the fluid pressure signal is kept as reference for the whole post processing.

Beyond the standard WT frequency analysis of singular signals, the Cross-Correlation and the calculation of the instantaneous angle of phase between the two signals at the evaporator and at the condenser is also performed to demonstrate that the last can be physically interpreted as a repeatable time shift between the two signals that can be used to evaluate the flow local mean velocity. The flow velocities values obtained by means of the WT analysis are finally compared to those obtained by the InfraRed visualization technique showing a good match and opening a new and valuable alternative for the PHP flow characterization where visualization techniques are not applicable. 


\subsection{Experimental equipment in Flight}

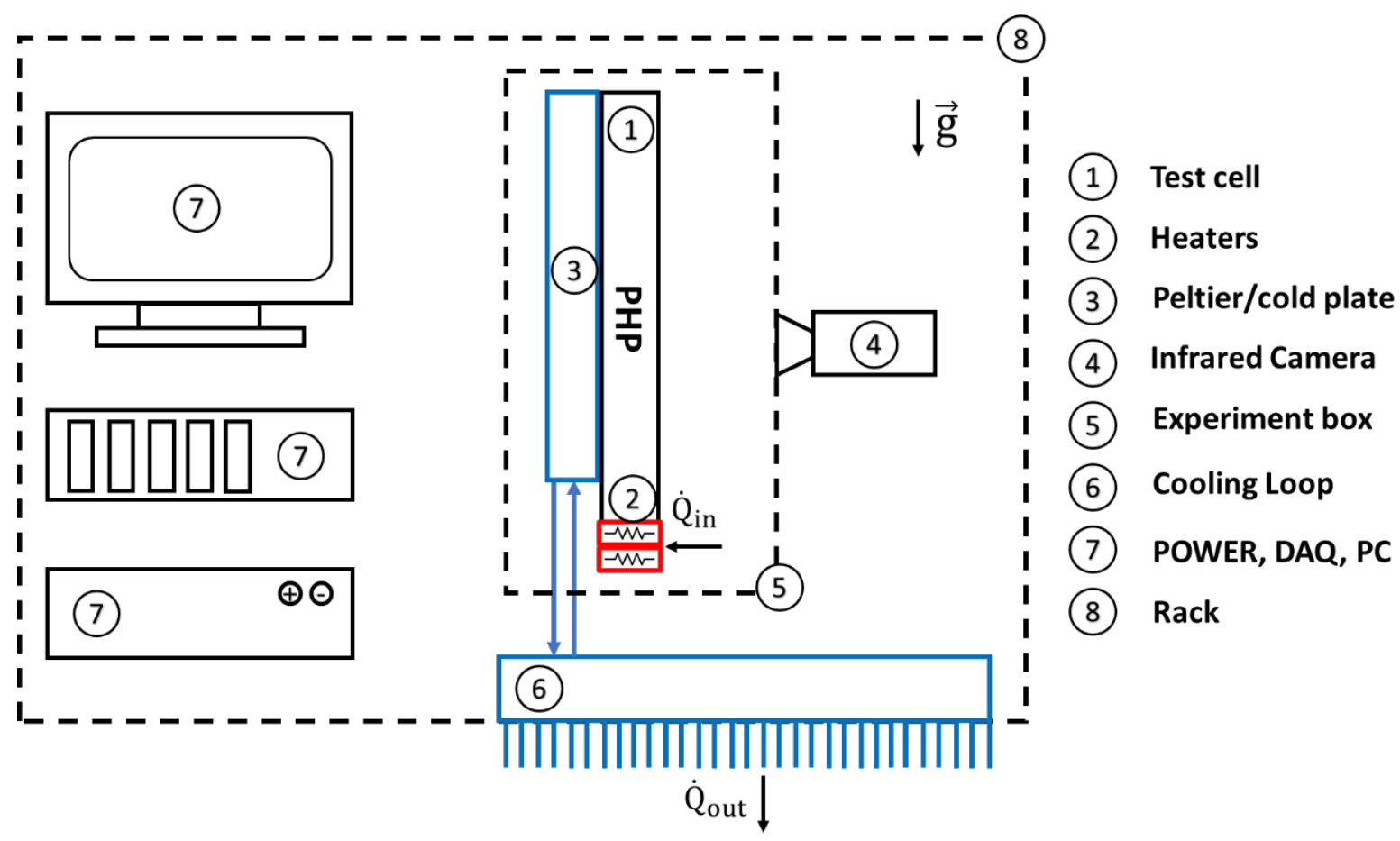

Figure 1: Overall experimental layout.

The experimental equipment in flight configuration is shown in Figure 1. It consists of the test cell (1) with two electric heating elements (2) in the evaporator zone. The condenser zone temperature is controlled by a Peltier cells array (3), coupled with a cold plate where distilled water is recirculated and cooled by a secondary cooling loop (6) able to dissipate the whole heating power. An infrared camera (4) allows to record the flow regimes and the fluid temperature distribution through the transparent section made of sapphire. Signals are acquired using a Data Acquisition system described in detail in the next sections (7). The subsystem containing fluids are inserted in a double containment (5) and finally, all the systems described above are mounted on a rack structure.

\subsection{Test cell}

The PHP test cell consists of an annealed aluminum tube with an inner/outer diameter of 3/5 $\mathrm{mm}$ and it is also thoroughly described by Mameli et al. [19]. The tube is folded in a single loop staggered configuration with fourteen turns in the evaporator zone as shown in Figure 2. 


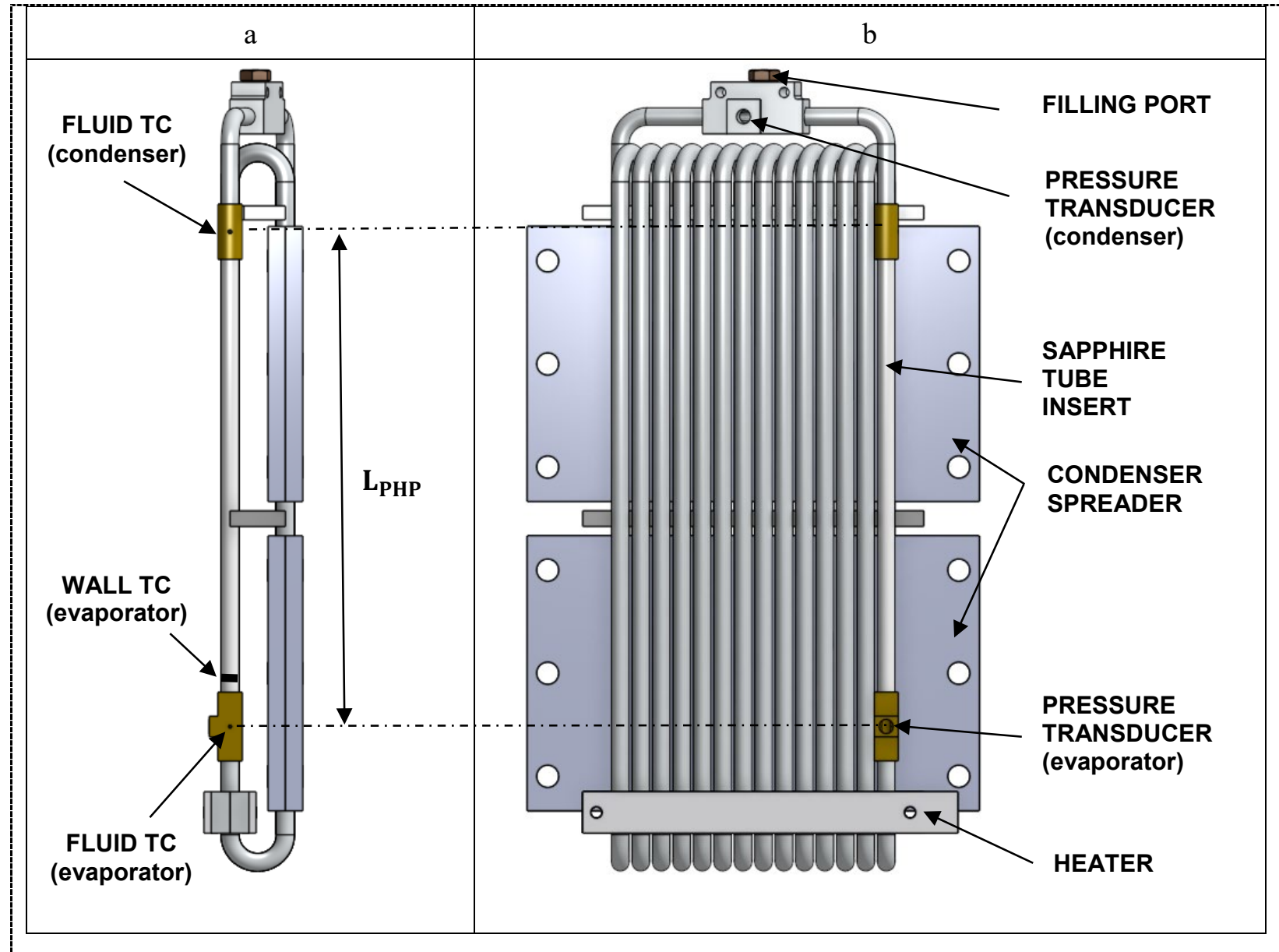

Figure 2 Test cell CAD (220x80x25 mm) side view (a) and front view (b) with pressure transducers and thermocouple locations of the fluid signals.

An aluminium T-junction (on the top of figure $2 \mathrm{~b}$ ) allows to close the loop and hosts a miniaturized pressure transducer along with the vacuum and filling port. Two brass connections allow to embed a sapphire tube insert, transparent (transmissivity 0.9) both to the visible and the Medium Wave InfraRed (MWIR), and to host two K-type micro-thermocouples for the fluid temperature measurement, as well as one pressure transducer close to the evaporator section. Two ceramic ohmic heaters supply from a minimum of $18 \mathrm{~W}$ to a maximum of $180 \mathrm{~W}$ by means of a programmable power supply, corresponding to an average wall to fluid heat flux from 1.10 to $11.43 \mathrm{~W} / \mathrm{cm}^{2}$. In particular, the tested heat input levels are $\dot{Q}=68,96,134,146 \mathrm{~W}$. The backside of the condenser spreaders is cooled down by means of eight Peltier cells and cold plate temperature control system (not shown in figure 2). The main measured variables along with the probes specifications and their maximum errors are shown in Table 2. The device is partially filled with $22 \mathrm{ml}$ of FC-72 (50\% vol.). The test rig is then loaded on an Airbus A310 and a total of 93 parabolic trajectories (hypergravity-microgravity-hypergravity) are performed over the three days of flight.The device is oriented in bottom heated mode (the main acceleration field in the flow path direction). During the thermal characterization, the device is 
heated up at the desired power level before the occurring of the microgravity period, and the power level is kept constant for the whole sequence of parabola. The pressure signals are acquired at $200 \mathrm{~Hz}$ and the temperature signals as well as the MWIR camera are acquired at $50 \mathrm{~Hz}$.

Table 2. Measured quantities and uncertainties.

\begin{tabular}{|c|c|c|}
\hline Parameter & Specs. & Max. error \\
\hline $\begin{array}{l}\text { Tube wall } \\
\text { temperature }\end{array}$ & T-Type thermocouples ( $0.5 \mathrm{~mm}$ bead diameter) & \pm 0.1 \\
\hline Fluid temperature & $\begin{array}{l}\text { Omega }{ }^{\circledR} \text { KMTSS-IM025E-150 K-Type thermocouples } \\
(0.25 \mathrm{~mm} \text { bead diameter })\end{array}$ & \pm 0.2 \\
\hline Fluid Pressure & Keller ${ }^{\circledR}$ PAA-M5-HB, 1 bar abs & \pm 500 \\
\hline $\begin{array}{l}\text { Fluid temperature in } \\
\text { sapphire section }\end{array}$ & AIM $^{\circledR}$ MWIR camera, (wavelength 3-5 $\mu \mathrm{m}$ ) & \pm 2 \\
\hline Power Input & GW-Instek ${ }^{\circledR}$, PSH-6006A & \pm 3 \\
\hline
\end{tabular}

\subsection{Infrared Analysis}

Since the sapphire tube is almost transparent to the radiation in the MWIR spectrum, the images, allowed to measure, not only the temperature distribution of liquid plugs, as already demonstrated in a previous work by the same authors [20], but also their length and velocity. The sapphire tube portion framed by the camera is $65.8 \mathrm{~mm}$ long and results in a $701 \mathrm{x} 54$ pixel image, therefore the pixel dimension is approximately $93 \mu \mathrm{m}$. Figure 3 shows two consequent time frames of the fluid temperature distribution (orange line) in the mid axis of the transparent extracted from the MWIR images. Note that only when the liquid phase fills completely the channel (liquid slugs), the temperature values are detectable (continuous line). For all the other cases, i.e. vapor bubbles, or dispersed flow, since the vapor phase is almost transparent to the MWIR spectrum, the corresponding temperature is not physically meaningful (dashed line). In any case, the transition regions between higher and lower temperatures correspond to the menisci of a liquid slug. A thorough image analysis is performed by means of a custom Matlab software to detect the liquid slug menisci at each frame and calculate their length and velocity. The liquid slug recognition is performed evaluating the local maxima and minima of the temperature first derivative (black line): a liquid plug is always detected between a maximum and a minimum. Being an adiabatic zone, no evaporation or condensation occurs while the slugs travels through the sapphire tube, thus slugs are expected to maintain the same length throughout all the recorded frames. Indeed, the maximum discrepancy in the length measurement between different frames is 5 pixels and this occurs for less than the $20 \%$ of the frames. The $i$-th slug velocity over one time step, i.e. between frame $k-1$ and frame $k$, is defined as

$$
v_{i, k}=\left(x_{i, k}-x_{i, k-1}\right) f_{a c}
$$


205

206

207

208

209

210

211

212

213

214

215

216

217

218

219

220

221

222

where $x_{i, k}$ is the $i$-th slug center point in frame $k, x_{i, k-1}$ is the $i$-th plug center point in frame $k-1$ and $f_{a c}$ is the acquisition frequency. It follows that the maximum uncertainty of the instantaneous velocity is $0.093 \cdot 10^{-3} \cdot 5 \cdot f_{a c} \cong 0.023 \mathrm{~m} / \mathrm{s}$. The mean velocity is finally evaluated as

$$
\bar{v}_{i, I R}=\frac{1}{N_{f}} \sum_{k=1}^{N_{f}} v_{i, k}
$$

where $N_{f}$ is the total number of frames. In this case, since the maximum discrepancy in the length measurement between different occurs for less than the $20 \%$ of the frames, the maximum uncertainty is tempered as follows $0.2 \cdot 0.093 \cdot 10^{-3} \cdot 5 \cdot f_{a c} \cong 0.004 \mathrm{~m} / \mathrm{s}$. The mean velocity values are used in section 3.6 as a reference for the comparison with the mean velocities extracted through the WT analysis.
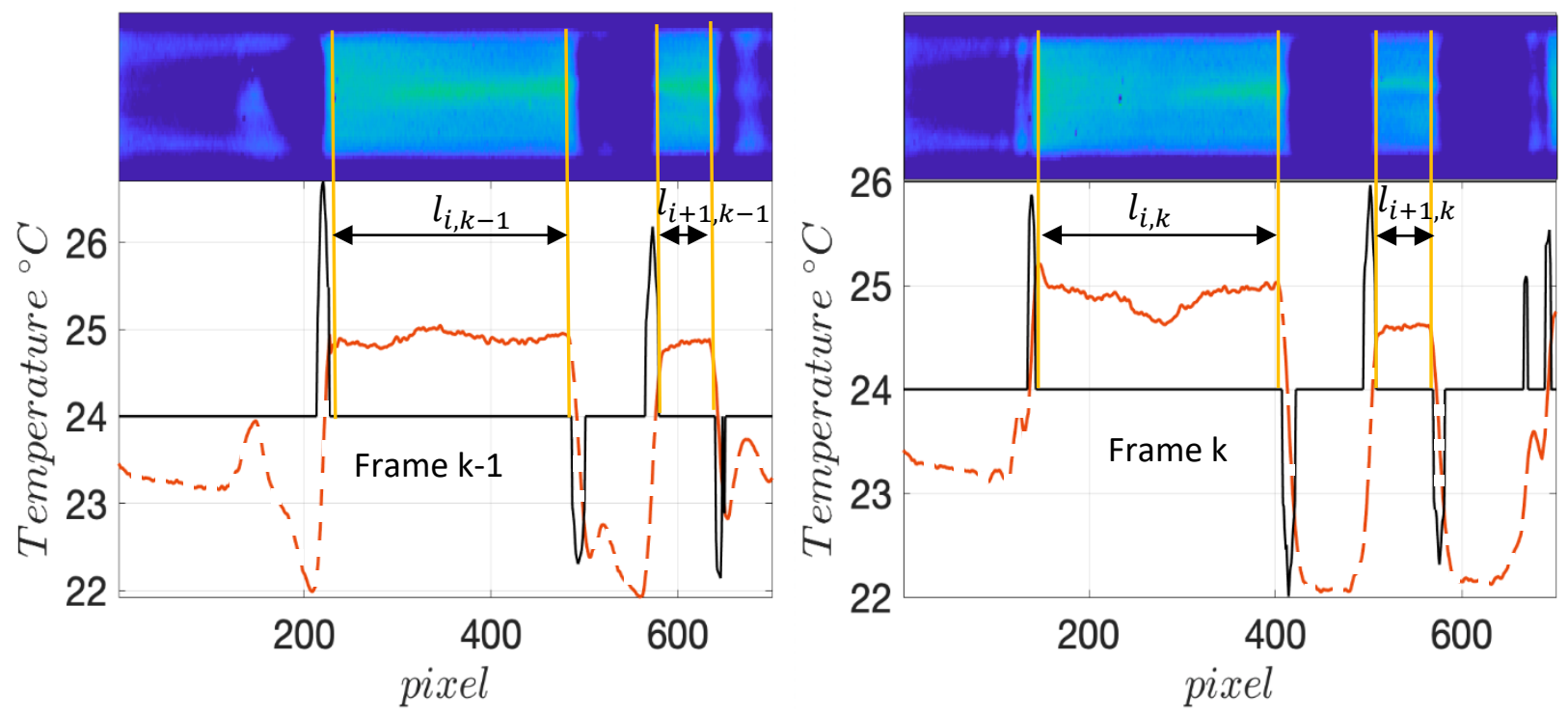

Figure 3: On top, IR images of the sapphire tube. On the bottom, the temperature distribution (orange), the first derivative of temperature distribution (black), plugs ends (yellow).

\subsection{Wavelet Transform methodology}

The fluctuations of the pressure and temperature signals are characterized through techniques based on the continuous Wavelet Transform (WT). As described by Buresti et al. [17], a wavelet function can be any real or complex function $\psi(t) \in L^{2}$ that satisfies the following admissibility condition:

$$
C_{\psi}=\int_{-\infty}^{+\infty}|\hat{\psi}(\omega)|^{2}|\omega|^{-1} d \omega<\infty
$$

where $\hat{\psi}(\omega)$ is the Fourier transform of $|\psi(t)|$. Indeed, to guarantee the reversibility of the 
value. Under this admissibility condition, the Wavelet Transform $W_{x}(a, \tau)$ can be defined as follows:

$$
W_{x}(a, \tau)=\frac{1}{\sqrt{a}} \int_{-\infty}^{+\infty} x(t) \psi^{*}\left(\frac{t-\tau}{a}\right) d t
$$

where $a \in \mathfrak{R}^{+}$is the scale dilation parameter and $\tau \in \mathfrak{R}$ is the translation parameter. In the present study, the complex Morlet wavelet $\psi(t)=e^{i \omega_{0} t} e^{-t^{2} / 2}$ is used, with a central frequency $\omega_{0}=2 \pi$ in order to well-balance time and frequency resolutions (Table 3). For the Morlet wavelet the frequencies $f$ are related to the scales $a$ by $f=\omega_{0} /(2 \pi a)$, thus in this case, $f=$ $1 / a$. The wavelet power spectrum can be obtained from the integration in time, i,e, for each scale/frequency, the wavelet energy map, as:

$$
P_{W_{x}}(a)=\frac{1}{C_{\psi}}\left|W_{x}(a, \tau)\right|^{2} d \tau
$$

In analogy to the signal analysis procedures used in [18], [21], the Wavelet Transform is preferred to STFT for time-frequency analysis because it allows to dynamically increase the frequency resolution at lower frequency values, whereas to increase time resolution at higher frequency values (in STFT a the frequency resolution is fixed). Moreover, compared to classical Fourier spectra, the wavelet-based procedure allows to obtain smoother spectra and well defined from the mathematical point of view. The results in the following section are reported in form of time-frequency energy maps $\left|W_{x}\right|^{2}$, (also called "scalograms") and wavelet spectra $P_{W_{x}}$. In the scalogram, the colour represents the energy value at the given time and frequency. The related spectrum will be used for the identification of the dominant frequencies. Given that $W_{x}(a, \tau)$ and $W_{y}(a, \tau)$ are, respectively, the complex wavelet transforms of two signals $x(t)$ and $y(t)$, their wavelet cross-scalogram is defined, as:

$$
\begin{aligned}
& W_{x-y}(a, \tau)=W_{x}^{*}(a, \tau) W_{y}(a, \tau)= \\
& \operatorname{CoW}_{x y}(a, \tau)-i \operatorname{Quad}_{x y}(a, \tau)
\end{aligned}
$$

It can be shown that the real part of the cross-scalogram, or co-scalogram $C_{0} W_{x y}$, gives the instantaneous contribution at each frequency scale to the correlation between the two signals. The instantaneous angle of phase, $\theta_{x-y}(a, \tau)$, can be expressed as:

$$
\theta_{x-y}(a, \tau)=\operatorname{tg}^{-1} \frac{\operatorname{Quad}_{x y}(a, \tau)}{\operatorname{CoW}_{x y}(a, \tau)}
$$

This formulation may be used to analyse the correlation between the fluctuations at a given frequency present in two simultaneously-acquired signals. When $\theta_{x-y}=0 \pm k 360 \mathrm{deg}$ the analyzed signals are perfectly in phase, whereas $\theta_{x-y}=180 \pm k 360 \mathrm{deg}$ indicates perfect phase opposition.

\section{Results and discussion}

The Wavelet analysis is performed on the pressure $\left(P_{f}\right)$, fluid temperature $\left(T_{f}\right)$ and wall temperature $\left(T_{w}\right)$ signals. The analysis is performed on a frequency range from 0.01 to $4 \mathrm{~Hz}$. For the processing of the signals, an in-house-developed wavelet tool has been used (see e.g. 
Table 3. Wavelet parameters.

\begin{tabular}{|c|c|c|c|}
\hline \multicolumn{2}{|c|}{$a$} & \multicolumn{2}{|c|}{401} \\
\hline \multicolumn{2}{|c|}{$\omega_{0}$} & \multicolumn{2}{|c|}{$2 \pi$} \\
\hline \multicolumn{2}{|c|}{$\mathrm{f}_{\min }[\mathrm{Hz}]$} & \multicolumn{2}{|c|}{0.01} \\
\hline \multicolumn{2}{|c|}{$\mathrm{f}_{\max }[\mathrm{Hz}]$} & \multicolumn{2}{|c|}{4} \\
\hline & Pressure & Temperature & g-level \\
\hline $\mathrm{f}_{\mathrm{ac}}[\mathrm{Hz}]$ & 200 & 50 & 5 \\
\hline $\mathrm{n}$ & 12 & 10 & 7 \\
\hline $\mathrm{N}_{\mathrm{Wt}}$ & 4096 & 1024 & 128 \\
\hline $\mathrm{t}_{\mathrm{an}}[\mathrm{s}]$ & 20.48 & 20.48 & 25.6 \\
\hline
\end{tabular}

262 The Wavelet analysis is conducted through the following steps:

263 a) choice of the relevant time range (Microgravity period);

264 b) definition of the dominant frequency;

265 c) analysis of gravity acceleration as a possible disturbance;

266 d) comparison of the Wavelet Scalogram and the Power Spectrum of the fluid pressure, fluid temperature and wall temperature signals;

e) determination of the Wavelet Scalogram and the Power Spectrum of the fluid pressure signal at each heat input level;

f) identification of the dominant frequency of the fluid pressure signal for each heat input level;

g) comparison between the fluid pressure signal recorded at the evaporator and the signal recorded at the condenser through wavelet cross scalogram, wavelet local correlation coefficient and instantaneous angle of phase;

h) identification of the mean instantaneous angle of phase at the dominant frequency between the fluid pressure signal recorded at the evaporator and at the condenser for each heat load input;

i) identification of the mean time lag and then the mean velocity at the dominant frequency between the fluid pressure signal recorded at the evaporator and the signal recorded at the condenser for each heat load input.

\subsection{The microgravity period}

As thoroughly explained in [19], since the tube diameter is larger than the capillary limit on ground, this kind of Pulsating Heat Pipe has been actually proved to operate as a series of Loop Thermosyphons when gravity is present, while it switches to the Pulsating Heat Pipe mode (oscillating slug flow) when the gravity field is absent, i.e. during the microgravity period of a parabolic flight. In this framework, the time frequency analysis of the fluid pressure signal gives 
the gravity field during a parabolic manoeuvre consisting of three periods: the first hypergravity (20 s) during the aircraft ascent, the microgravity period at the top of the parabola (20s) and the second hyper-gravity period (20 s) during the aircraft recovery. Figure $4 \mathrm{~b}$ shows the temporal trend of the fluid pressure signal close to the evaporator zone synchronized with the gravity trend, where the red lines highlight the microgravity period. The sudden change in the fluid pressure fluctuation is clearly visible in terms of amplitude during the microgravity period but it is only the wavelet processing of the fluid pressure signal that reveals, by means of the scalogram (Figure 4c), the existence of energy peaks, apparently at a given frequency only during the microgravity period. For these reasons the WT analysis have been performed for all the heat input levels only during the microgravity duration. The different temporal trend of fluid temperature and fluid pressure at the evaporator zone (red line) and at the condenser zone (blue line), for each load input is shown in Figure 5.

Figure 4: a) g-level and b) fluid pressure temporal trend during a typical flight parabola, c) Wavelet

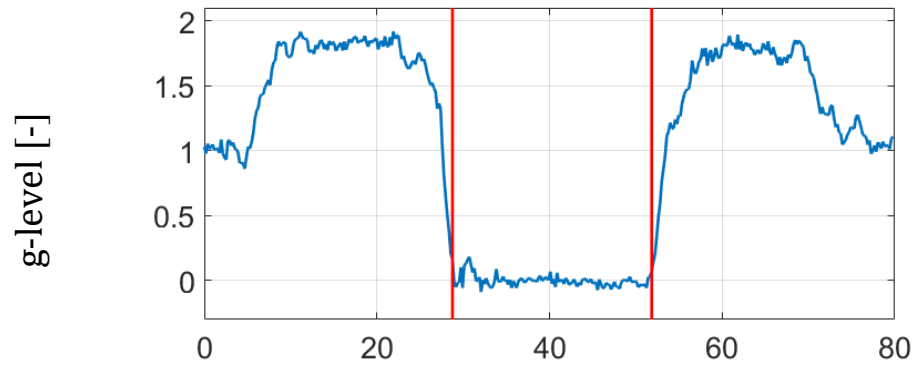

a)

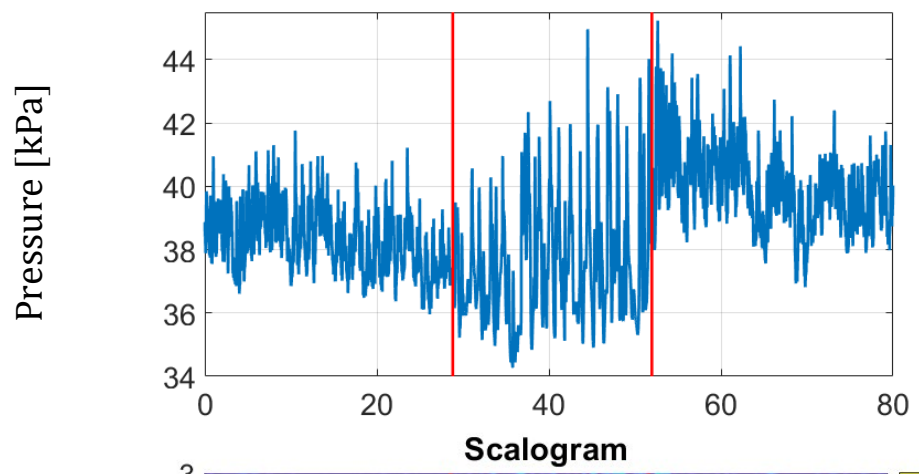

b)

\section{c)}

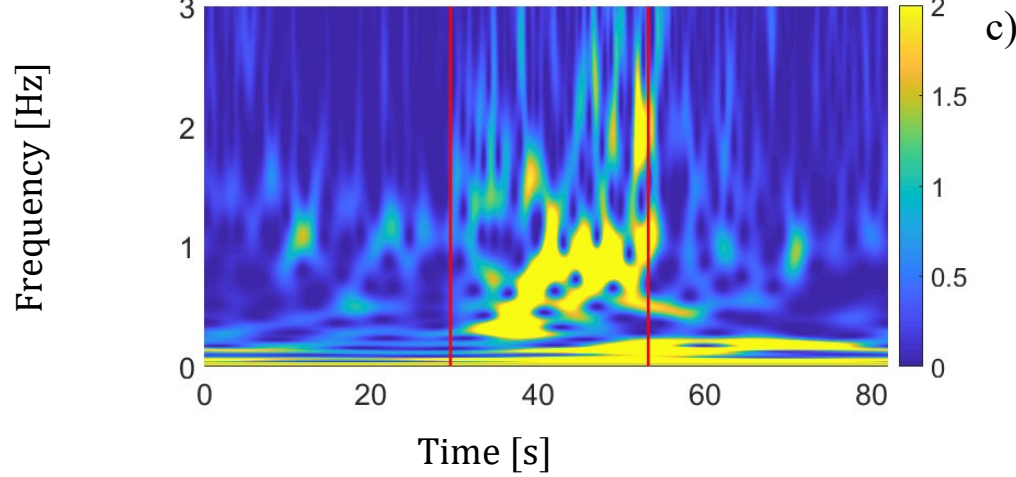
scalogram. 


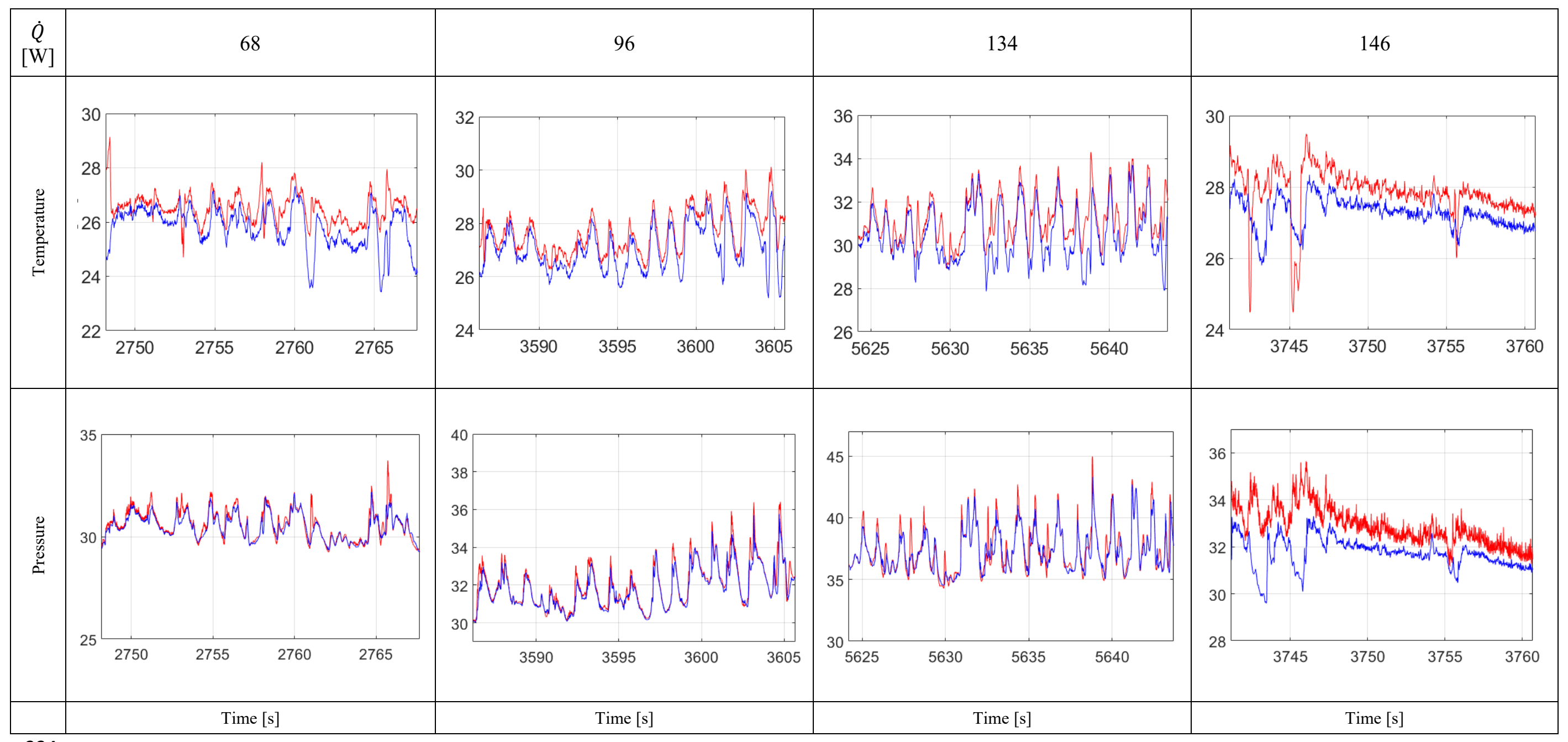

Figure 5: temporal trend of the fluid pressure and fluid temperature at the evaporator zone (red line) and at the condenser zone (blue line), for each heat load input. 


\subsection{Definition of dominant frequency}

Given the wavelet power spectrum $\mathrm{P}_{\mathrm{Wt}}(\mathrm{f})$, in the domain $\operatorname{Dom}\left(\mathrm{P}_{\mathrm{Wt}}\right)$, the dominant frequency $\left(f_{D}\right)$ shall be defined as the frequency at which the absolute maximum of the function is $\mathrm{P}_{\mathrm{Wt}}(f)$ occur. Thus, from an analytical point of view:

$$
\forall f \in \operatorname{Dom}\left(\mathrm{P}_{\mathrm{Wt}}\right) \quad \mathrm{P}_{\mathrm{Wt}}(\mathrm{f})<\mathrm{P}_{\mathrm{Wt}}\left(\mathrm{f}_{\mathrm{D}}\right)
$$

Since the wavelet power spectrum $\mathrm{P}_{\mathrm{Wt}}(\mathrm{f})$ may present more than one peak, relative-maximum frequencies, also called characteristic frequencies, are also defined. The relative-maximum frequencies $\mathrm{f}_{\mathrm{C}}$ exist if $\exists \operatorname{SubDom}\left(\mathrm{P}_{\mathrm{Wt}}\right)$ with $f_{D} \notin \operatorname{SubDom}\left(\mathrm{P}_{\mathrm{Wt}}\right)$ such that:

$$
\forall f \in \operatorname{SubDom}\left(\mathrm{P}_{\mathrm{Wt}}\right) \quad \mathrm{P}_{\mathrm{Wt}}(\mathrm{f}) \leq \mathrm{P}_{\mathrm{Wt}}\left(\mathrm{f}_{\mathrm{C}}\right)
$$

The dominant frequency $\left(f_{D}\right)$ will be indicated in the Scalogram and in the Power Spectrum graphs as a black dashed line instead the characteristic, or secondary, frequency $\left(\mathrm{f}_{\mathrm{C}}\right)$ as a black solid line (Figure 6b). Once defined the dominant and the characteristic frequencies from the wavelet spectrum, it is possible to evaluate also their temporal continuity from the scalogram. Notice that such a rigorous procedure allows to compare the results of different authors according to a unique analytical definition.

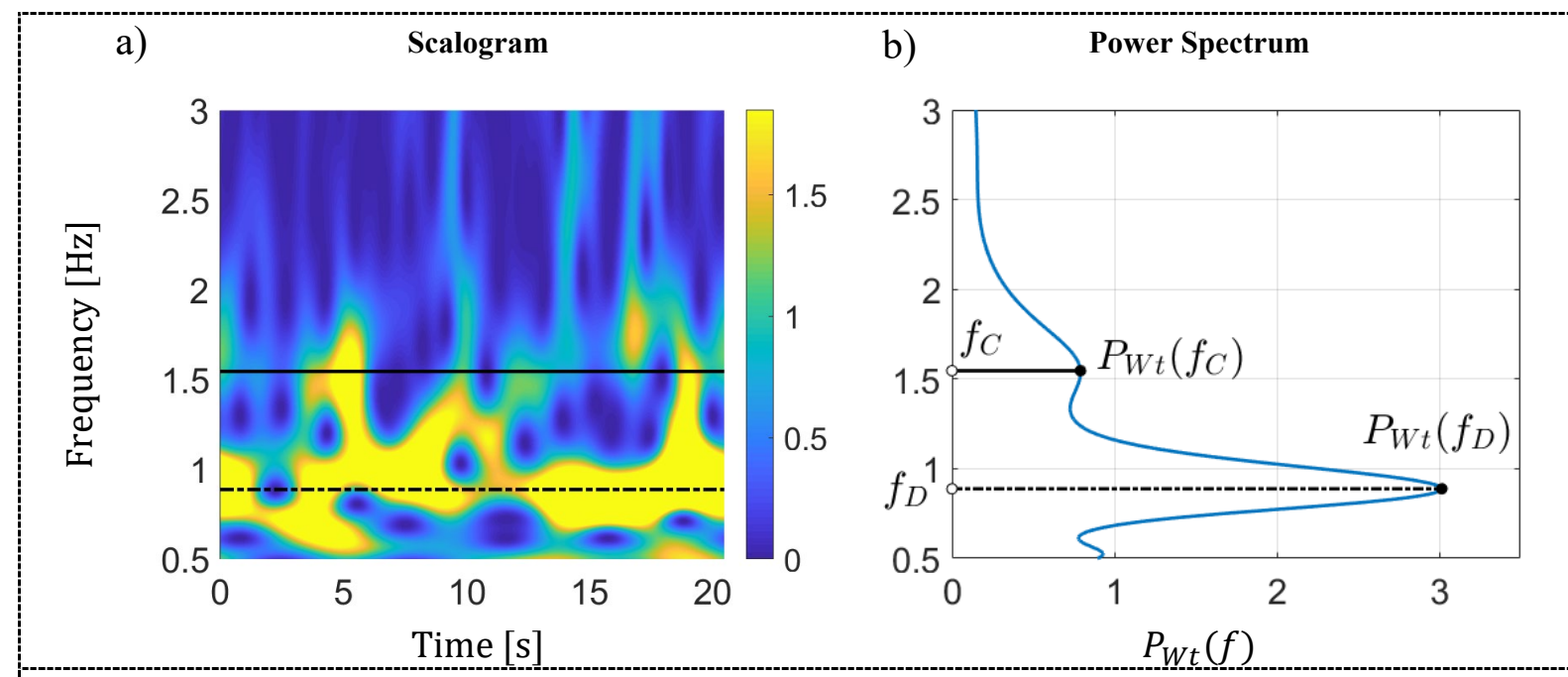

Figure 6: a) Example of Scalogram b) Power Spectrum where the dominant frequency and the characteristic frequency are identified.

\subsection{Noise}

The gravitational acceleration $\mathrm{g}$ signal is analysed too by means of the WT method to ensure that the aircraft g-gitter does not add spurious frequencies to the pressure or temperature signals. In this case, the acquisition frequency is $\mathrm{f}_{\mathrm{ac}}^{\mathrm{g}}=50 \mathrm{~Hz}, \mathrm{~N}_{\mathrm{Wt}}^{\mathrm{g}}=128$ is chosen for the analysis time $\mathrm{t}_{\mathrm{an}}^{\mathrm{g}}=25.6 \mathrm{~s}$, and with the g-level range $-0.1 \leq g \leq 0.1$ (Figure 6a). In the Wavelet Scalogram and in the Power Spectrum, there are not dominant or characteristic frequencies, as show in Figure $6(b-c)$. Although the magnitude of the energy contribution of the $g$ signal is almost negligible, the frequency limit $f \geq 0.5 \mathrm{~Hz}$ (red hatch) ensures a noise-free analysis. 

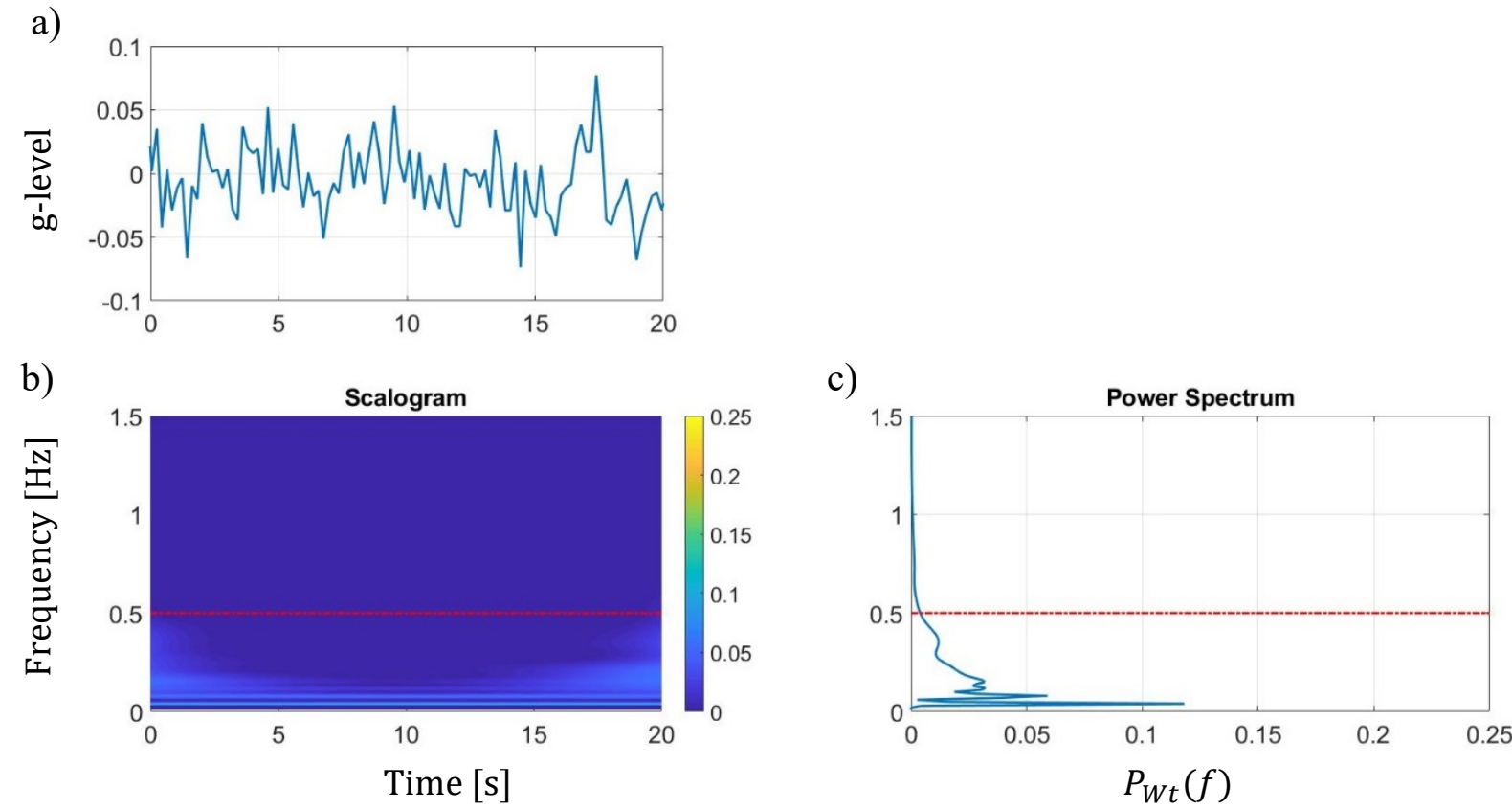

359 Figure 7: a) g-level temporal trend from the accelerometer; b) Wavelet Scalogram and c) Power 360 Spectrum.

\section{$3613.4 \quad$ Signal choice}

362 This section compares the results of WT analyses obtained using different signals, fluid pressure $363\left(P_{f}^{e}\right)$, fluid temperature $\left(T_{f}^{e}\right)$ and wall temperature $\left(T_{w}^{e}\right)$ signals recorded in the evaporator zone 364 during the same time interval. For the pressure signal, the acquisition frequency is $\mathrm{f}_{\mathrm{Ac}}^{\mathrm{P}}=200 \mathrm{~Hz}$ 365 and $\mathrm{N}_{\mathrm{Wt}}^{\mathrm{P}}=4096$ is chosen for an analysis time $\mathrm{t}_{\mathrm{An}}^{\mathrm{P}}=20.48 \mathrm{~s}$. Instead, for the temperature 366 signal, the acquisition frequency is $\mathrm{f}_{\mathrm{Ac}}^{\mathrm{T}}=50 \mathrm{~Hz}$ and $\mathrm{N}_{\mathrm{Wt}}^{\mathrm{T}}=1024$ is chosen for an analysis 367 time $\mathrm{t}_{\mathrm{An}}^{\mathrm{T}}=20.48 \mathrm{~s}$. The Scalograms for each signal are shown in Figure 8 and the Power 368 Spectrum of all three signals in a unique plot ( $P_{f}^{e}, T_{f}^{e}, T_{w}^{e}$ respectively blue, green, black line). 369 The fluid temperature signal appears to have the same dominant frequency as the pressure 370 signal, with a lower energy content. The wall temperature signal, instead, does not show 371 appreciable results in any frequency range, also according to Monroe at al. [13], and this is due 372 to the thermal impedance of the tube wall: the PHP envelope and its thermal inertia act as a 373 low-pass filter RC circuit on the signal. For these reasons, this work considers only the pressure 374 signal at the evaporator $P_{f}^{e}$ and condenser $P_{f}^{c}$. 


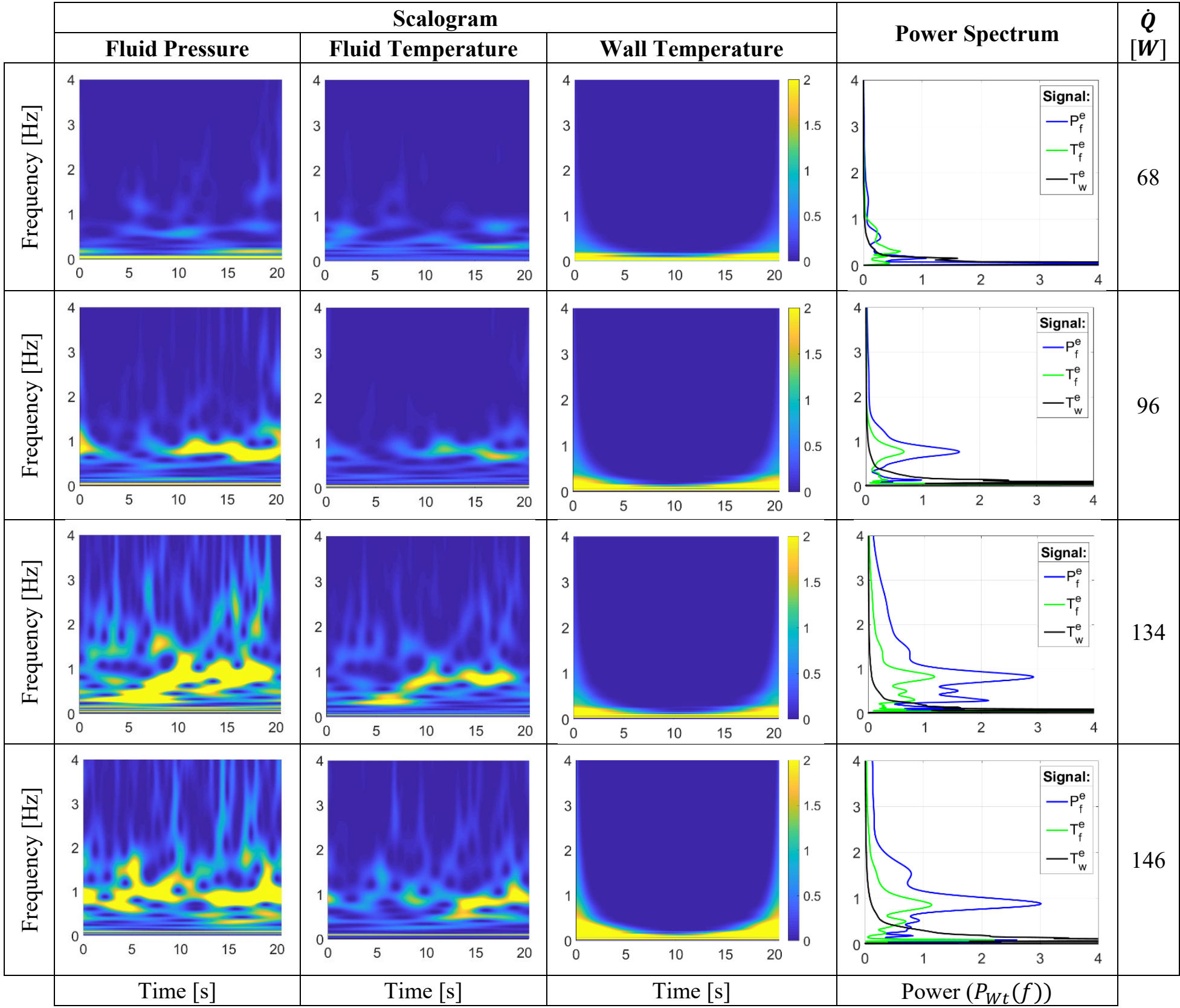

376 Figure 8: Wavelet Scalogram and Power Spectrum of the fluid pressure signal ( $P_{f}^{e}$ blue line), the fluid

377 temperature ( $T_{f}^{e}$ green line) and the wall temperature ( $T_{w}^{e}$ black line), for each heat load input.

\subsection{Pressure signal wavelet analysis}

379 The Wavelet Scalogram and Power Spectrum of a pressure signal at the evaporator section for

380 each heat load level are represented in Figure 9, respectively. Also, the pressure signal at the 381 condenser section is analysed, and the results are listed in Table 4. From a physical point of 382 view, the two signals can be shifted or damped in terms of oscillation amplitude (Section 3.6), 383 but the frequency is the same. The dominant frequency is identified by the black dashed line 384 and by the value as shown in Section 3.2. The dominant frequency falls in the range $0.6-0.9$ 385 Hz. Since each heat input level has been tested at least four times to guarantee repeatability, all 
the results are analysed, compared and summarized in Figure 10 resuming the dominant

387 frequency (y-axis) occurring at each power input (x-axis). A linear interpolation of all the data

388 (dashed line in figure 10) shows that the value of the dominant frequency increases with 389 increasing heat load input.

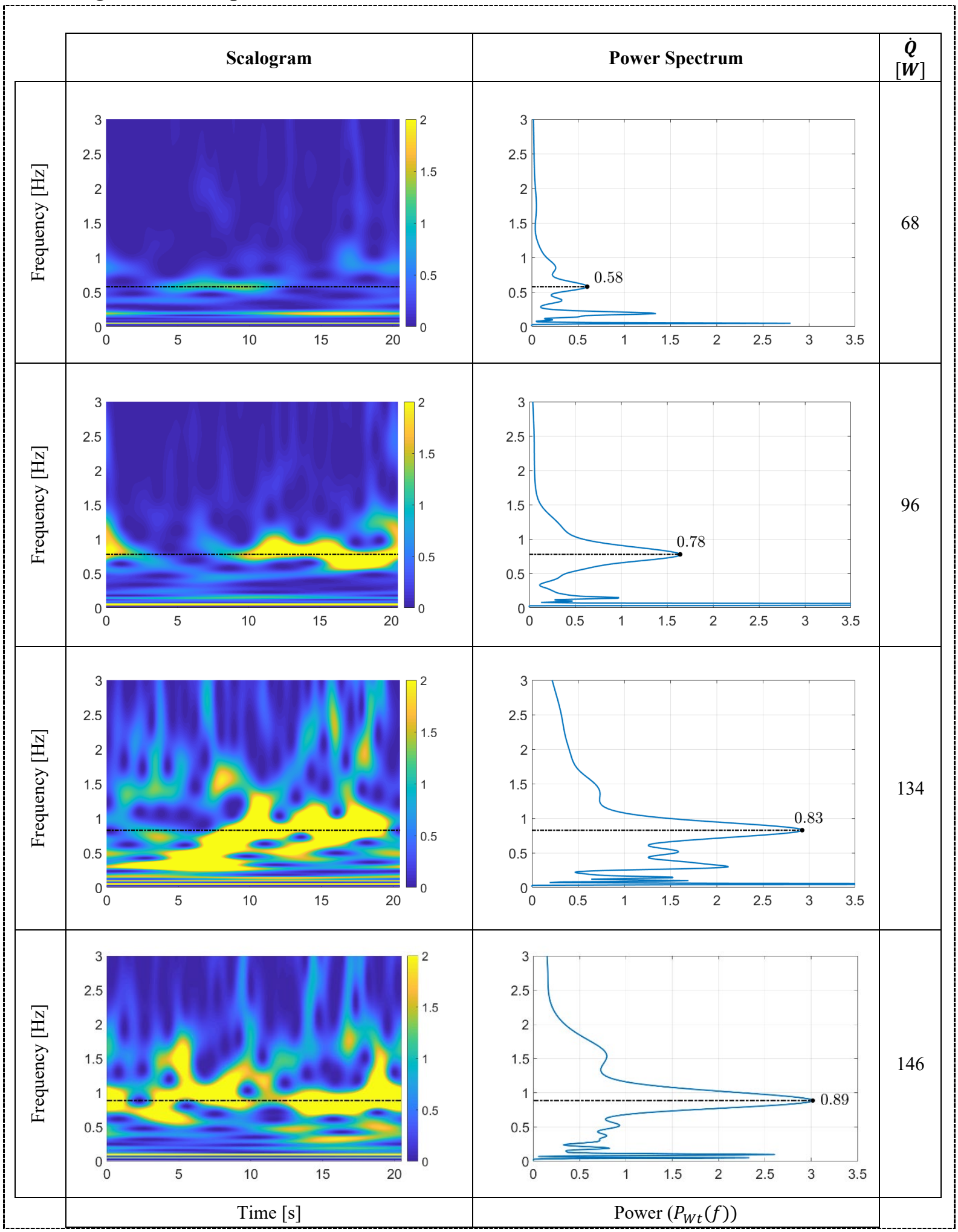


Figure 9: Wavelet Scalogram and Power Spectra of the fluid pressure signal $\left(P_{f}^{e}\right)$ at each heat load input

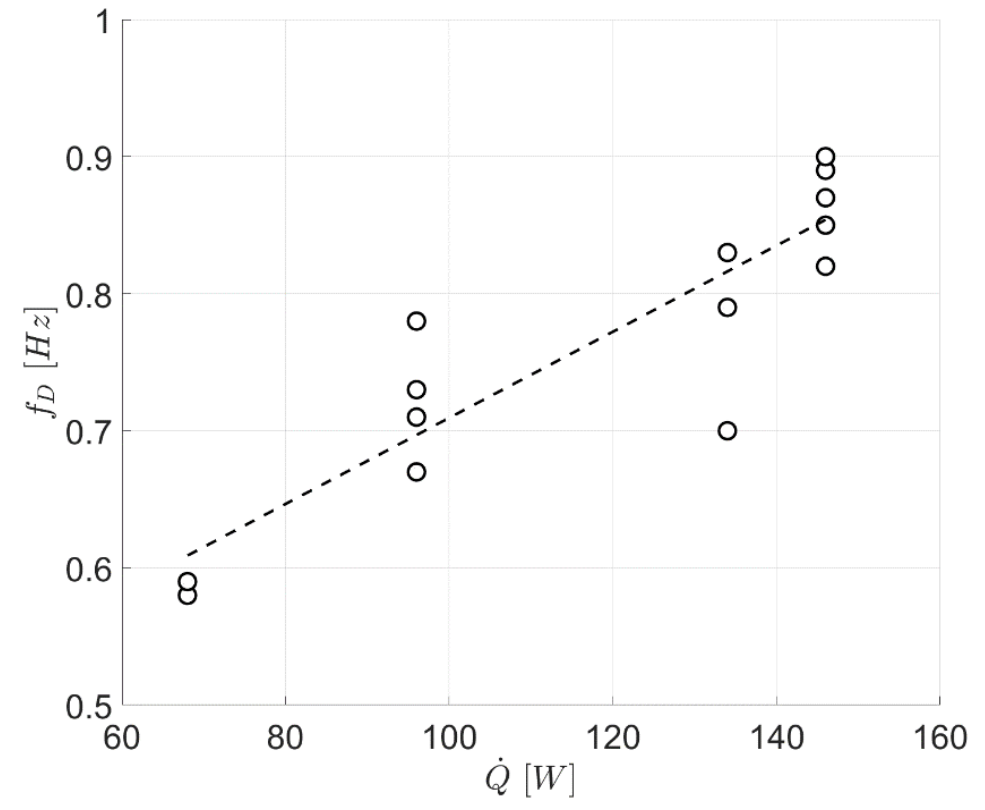

Figure 10: Dominant frequency trend with increasing heat load input of the fluid pressure signal.

\subsection{Cross correlation and fluid mean velocity}

As shown in Section 2.3, the co-scalogram of the cross-wavelet transform identifies the frequencies where energy peaks are present both for the evaporator $\left(P_{f}^{e}\right)$ and the condenser $\left(P_{f}^{c}\right)$ (Figure 11 a). Their contribution to the correlation is derived from the Instantaneous Angle of Phase, $\theta_{e-c}$ (Figure $11 \mathrm{~b}$ ). As often happens, since trends are not clearly detectable, $\theta_{e-c}$ plots have been filtered by using the cross scalogram as mask (Figure $11 \mathrm{c}$ ). 


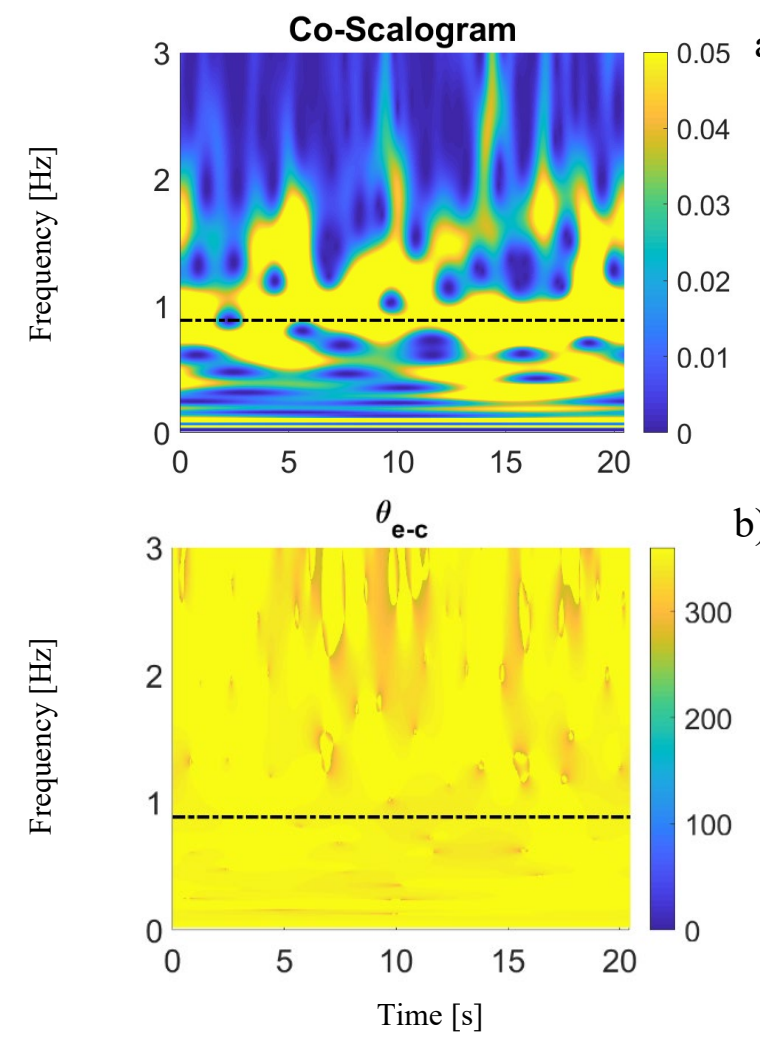

b)

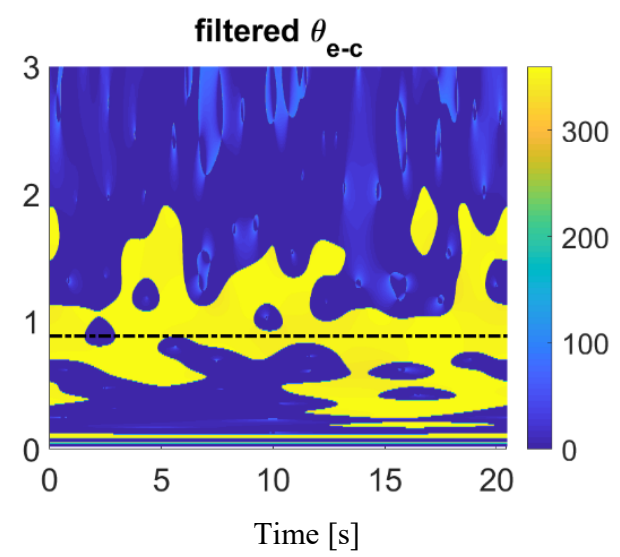

c)

Figure 11: comparison between the fluid pressure signal at the evaporator $\left(P_{f}^{e}\right)$ and the fluid pressure signal at the condenser $\left(P_{f}^{c}\right)$. Wavelet Cross Scalogram (a). Instantaneous angle of phase $\theta_{e-c}(\mathrm{~b})$ and related filtered (c).

407 Later, these filtered plots are integrated over time, obtaining the mean filtered $\left.\bar{\theta}_{e-c}\right|_{f_{D}}$ plot as 408 shown in the second column of Figure 12. The plots in the third column display the residual 409 points percentage (r.p. [\%]), i.e. the fraction of meaningful data after the filtering procedure. 410 The r.p. percentage obtained at $68 \mathrm{~W}$ is below the $50 \%$, meaning that data are not reliable after 411 the filtering procedure. All the other power levels show r.p. percentages above $70 \%$, meaning 412 that the most of data fall close to the dominant frequency. The mean filtered $\left.\bar{\theta}_{e-c}\right|_{f_{D}}$ is between $413 \quad 350 \mathrm{deg}$ and $355 \mathrm{deg}$ at high heat load inputs and $311 \mathrm{deg}$ at low heat load input. 


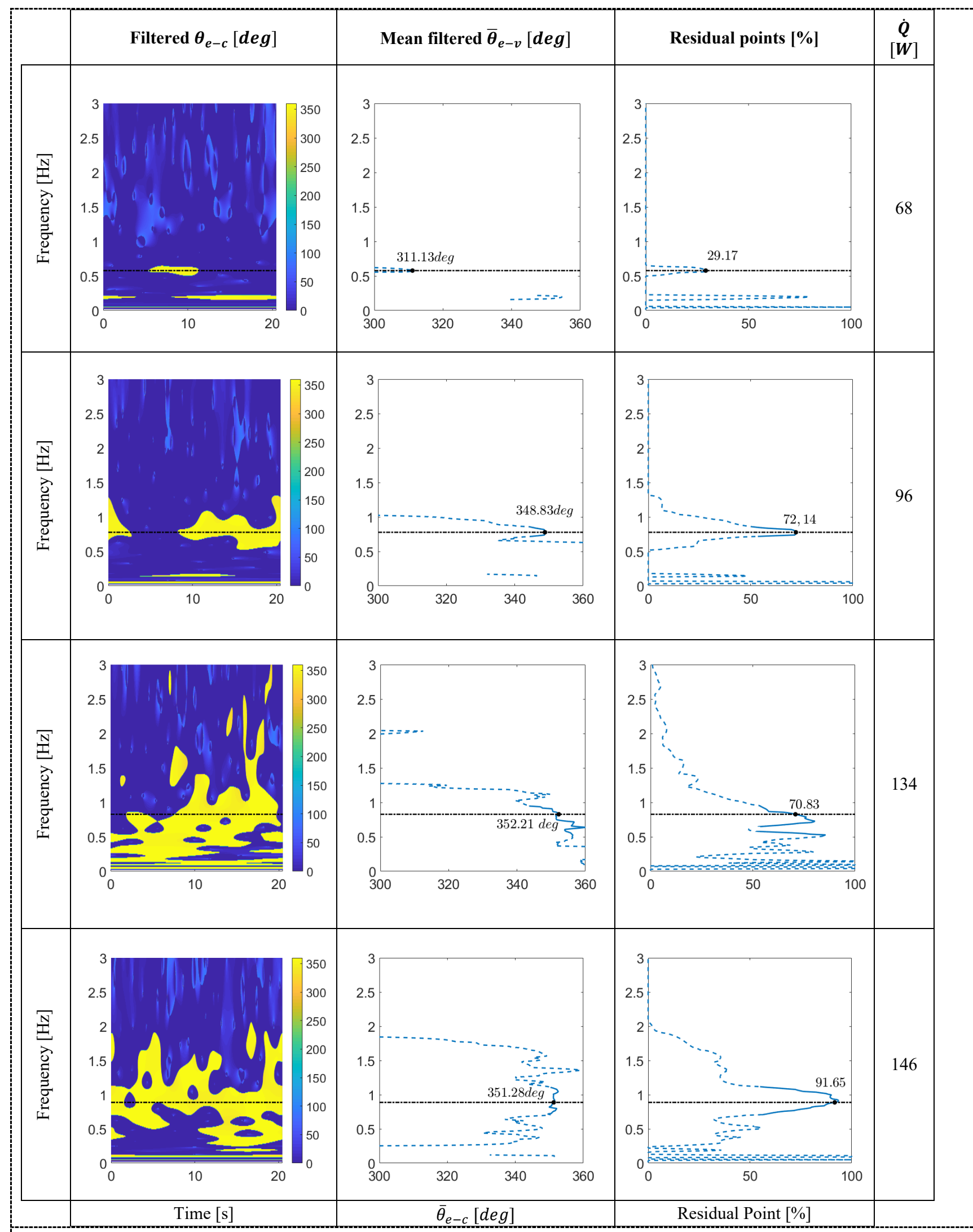

Figure 12: Filtered instantaneous angle of phase $\theta_{e-c}$, mean filtered instantaneous angle of phase $\bar{\theta}_{e-c}$ and residual point for each heat load input. 
414

415

416

Moreover, assuming the two signals have the same dominating frequency $f$, the time lag between two signals can be evaluated. In particular, the mean time lag $\left.\bar{t}_{e-c}\right|_{f}$ between the two signals $P^{e}(t)$ and $P^{c}(t)$ at a given frequency $f$ is:

$$
\left.\bar{t}_{e-c}\right|_{f_{D}}=\frac{\left.\bar{\theta}_{e-c}\right|_{f_{D}}}{360 f_{D}}
$$

417 where $\left.\bar{\theta}_{e-c}\right|_{f}(a)$ is the mean angle over time at the given frequency $f$ (one value for each given

418

419

420

421

422

423

424 a). Values of $\left.\bar{t}_{e-v}\right|_{f_{D}}$ fall in the range $1.5-1.1 \mathrm{~s}$. Assuming a Eulerian frame, the mean phase shift between the two pressure signals can be interpreted as the mean time needed by a batch of fluid to travel from the evaporator to the condenser. So, in first approximation, the mean time shift between the two pressure signals can be related to the fluid mean velocity of the fluid batch moving between the evaporator and the condenser as follows:

$$
\left.\bar{v}_{e-c}\right|_{f_{D}}=\frac{L}{\left.\bar{t}_{e-c}\right|_{f_{D}}}
$$

where $L=L_{P H P}=0.14 \mathrm{~m}$ is the distance between the evaporator and condenser measurement points as shown in figure 1 .

\begin{tabular}{|c|c|c|c|c|c|c|c|c|c|}
\hline DAY & $\mathrm{p}$ & $\begin{array}{c}\dot{Q} \\
{[W]}\end{array}$ & $\begin{array}{c}f_{D}^{e} \\
{[\mathrm{~Hz}]}\end{array}$ & $\begin{array}{c}f_{D}^{c} \\
{[\mathrm{~Hz}]}\end{array}$ & $\begin{array}{c}r .\left.p \cdot\right|_{f_{D}} \\
{[\%]}\end{array}$ & $\begin{array}{c}\left.\bar{\theta}_{e-c}\right|_{f_{D}} \\
{[\mathrm{deg}]}\end{array}$ & $\begin{array}{c}\left.\bar{t}_{e-c}\right|_{f_{D}} \\
{[s]}\end{array}$ & $\begin{array}{c}\left.\bar{v}_{e-c}\right|_{f_{D}}= \\
\bar{v}_{W T} \\
{[\mathrm{~m} / \mathrm{s}]}\end{array}$ & $\begin{array}{c}\bar{v}_{I R} \\
{[\mathrm{~m} / \mathrm{s}]}\end{array}$ \\
\hline $\mathrm{I}$ & 8 & 68 & 0.58 & 0.58 & 29.17 & 311.13 & 1.49 & 0.09 & 0.08 \\
\hline $\mathrm{I}$ & 24 & 68 & 0.59 & 0.58 & 25.88 & 338.91 & 1.60 & 0.09 & 0.06 \\
\hline $\mathrm{I}$ & 11 & 96 & 0.78 & 0.78 & 72.14 & 348.83 & 1.25 & 0.11 & 0.12 \\
\hline $\mathrm{I}$ & 12 & 96 & 0.73 & 0.73 & 57.64 & 355.49 & 1.36 & 0.10 & 0.08 \\
\hline $\mathrm{I}$ & 14 & 96 & 0.71 & 0.71 & 80.52 & 353.55 & 1.39 & 0.10 & - \\
\hline $\mathrm{I}$ & 15 & 96 & 0.67 & 0.68 & 47.46 & 344.90 & 1.43 & 0.10 & 0.08 \\
\hline $\mathrm{I}$ & 16 & 134 & 0.70 & 0.70 & 77.39 & 357.06 & 1.42 & 0.10 & - \\
\hline I & 17 & 134 & 0.83 & 0.83 & 70.83 & 352.21 & 1.18 & 0.12 & 0.11 \\
\hline $\mathrm{I}$ & 18 & 134 & 0.83 & 0.82 & 69.02 & 352.31 & 1.18 & 0.12 & - \\
\hline I & 19 & 134 & 0.79 & 0.79 & 80.47 & 342.48 & 1.21 & 0.12 & - \\
\hline II & 11 & 146 & 0.85 & 0.86 & 93.92 & 353.96 & 1.16 & 0.12 & - \\
\hline II & 12 & 146 & 0.89 & 0.88 & 91.65 & 351.28 & 1.10 & 0.13 & 0.13 \\
\hline II & 13 & 146 & 0.82 & 0.84 & 72.46 & 352.38 & 1.20 & 0.12 & 0.11 \\
\hline II & 14 & 146 & 0.87 & 0.70 & 80.66 & 356.00 & 1.14 & 0.12 & 0.11 \\
\hline II & 15 & 146 & 0.90 & 0.87 & 81.23 & 354.87 & 1.10 & 0.13 & - \\
\hline
\end{tabular}

Table 4. Resume of the wavelet analysis results.

The mean velocity $\left.\bar{v}_{e-c}\right|_{f_{D}}$ have been calculated for each parabola and falls in the range 0.09 $0.13 \mathrm{~m} / \mathrm{s}$. All the data collected are summarized in the Table 4 . This order of magnitude is comparable with the velocity values obtained with infrared analyses described in subsection 2.2, summarized in the last column of Table 4.

The velocity values achieved from the wavelet analysis $\left(\left.\bar{v}_{e-c}\right|_{f_{D}}=\bar{v}_{W T}\right)$ and from the infrared analysis $\left(\bar{v}_{I R}\right)$ were also compared in the $v / \dot{Q}$ plot (Figure 13). 
432

433

434

435

436

437

438

439

Figure 13 shows that the value of the mean velocity increases with increasing heat load input. The repeatability of the results is indicated by the white/grey/black colours. For instance, as show in Table 4, at $\dot{Q}=134 \mathrm{~W}$, the results $\left.\bar{v}_{e-c}\right|_{f_{D}}=0.12 \mathrm{~m} / \mathrm{s}$ is repeated three times (black dots in Figure 11), while $\left.\bar{v}_{e-c}\right|_{f_{D}}=0.10 \mathrm{~m} / \mathrm{s}$ is repeated one time (white dot in Figure 13). The results shows that the velocity is not much sensitive to frequency variations of $\Delta f=$ $0.04 \mathrm{~Hz}\left(0.79<f_{D}<0.83\right)$, while it varies for $\Delta f=0.13 \mathrm{~Hz}\left(0.70<f_{D}<0.83\right)$, at heat load input given $(\dot{Q}=134 \mathrm{~W})$.

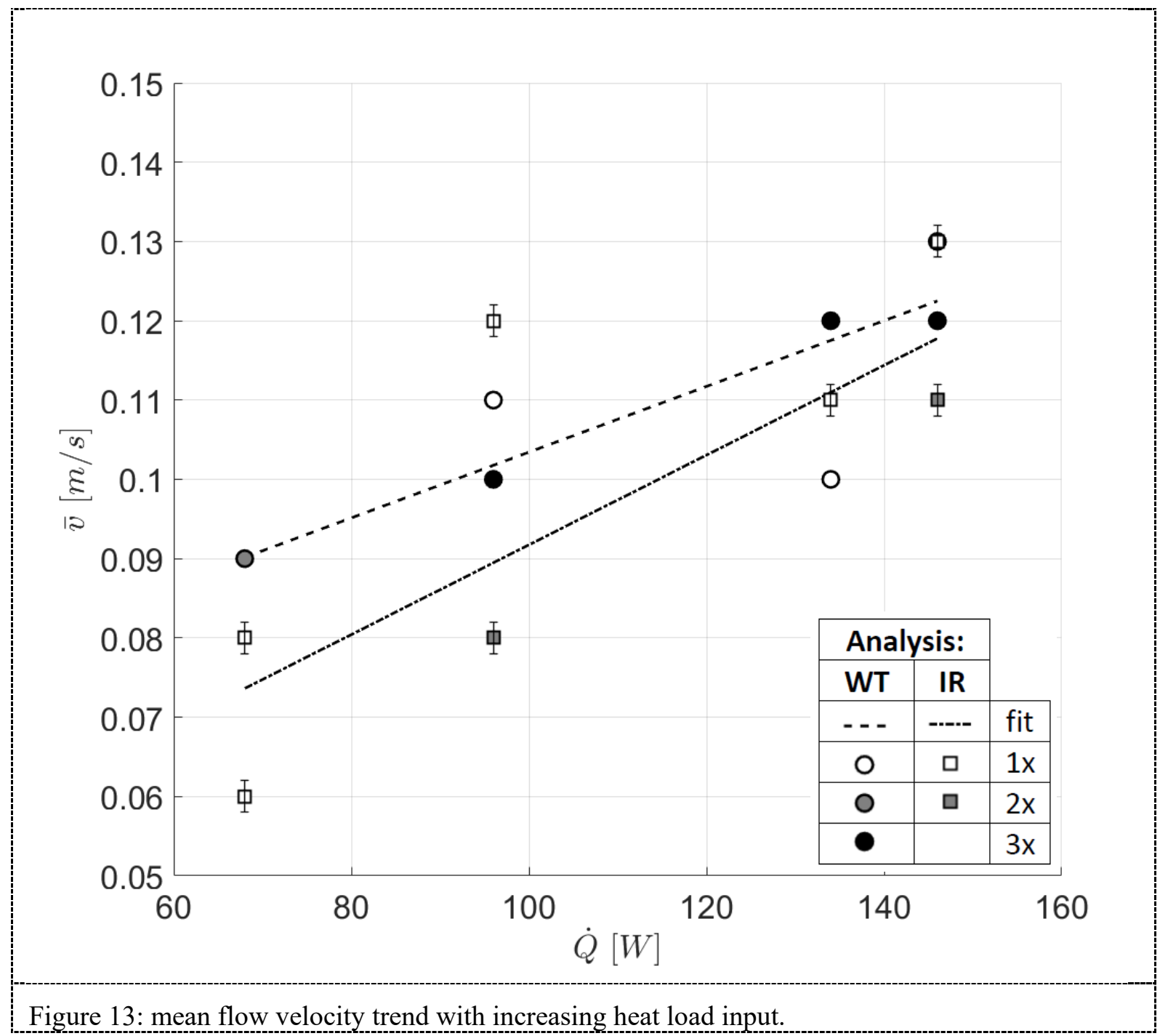

Investigating the fluid motion by means of two pressure transducers combined with the time frequency analysis, constitute a novel and promising tool that allows to provide an order of magnitude of the fluid mean velocity without any visualization technique, thus simplifying the experimental hardware.

\section{Conclusions}

445 The fluid pressure signals at the evaporator and the condenser of a Pulsating Heat Pipe tested 446 in microgravity conditions and with varying heat load input have been processed through a 
wavelet analysis to provide a rigorous definition of dominant frequency in the fluid motion. The investigation also allowed to relate the dominant frequencies to the heat input levels and, finally to provide an esteem of the mean flow velocity through the cross correlation between the two signals. In the light of literature review, the main outcomes of the present work are:

- the wall temperature signal of the hybrid PHP cannot be used for Wavelet analysis, due to the thermal impedance of the tube wall while the pressure signal is the most suitable;

- in general, the dominant frequency should be defined as the frequency related to the absolute maximum in the Power spectrum;

- the value of the dominant frequency of the pressure signals falls in the range $0.6-0.9 \mathrm{~Hz}$ and increases with increasing heat load input;

- the cross correlation between the two pressure signals allow to evaluate the mean phase shift, which itself can be related to the mean oscillating flow velocity. For the present case it falls in the range $0.09-0.13 \mathrm{~m} / \mathrm{s}$ and increases with increasing heat load input which is physically consistent;

- the velocity values obtained from the wavelet analysis and from the infrared analysis were in good agreement.

The possibility to investigate the average local fluid mean velocity only by means of pressure signals processed with a wavelet tool, constitutes an important step forward the characterization of the PHP behaviour and towards the validation of analytical and numerical PHP models. Furthermore, this method may in some case replace the visualization inserts and peripheral facilities (i.e. cameras). The complexity and cost of the measurements may be effectively reduced, leading to greater overall reliability both in the scientific and industrial field.

\section{References}

[1] Saha S.K., Celata G.P., "Instability in Flow Boiling in Microchannels", Springer Briefs in Applied Sciences and Technology, 2016.

[2] M. Rao, F. Lefèvre, P. C. Czujko, S. Khandekar, and J. Bonjour, "Numerical and experimental investigations of thermally induced oscillating flow inside a capillary tube," International Journal of Thermal Sciences 115, (2017) 29-42.

[3] J. S. Kim, N. H. Bui, H. S. Jung, and W. H. Lee, "The study on pressure oscillation and heat transfer characteristics of oscillating capillary tube heat pipe," KSME International Journal 17 (10) (2003) 1533-1542.

[4] J. L. Xu and X. M. Zhang, "Start-up and steady thermal oscillation of a pulsating heat pipe," Heat and Mass Transfer/Waerme- und Stoffuebertragung 41, (8) (2005) 685-694.

[5] S. Khandekar, A. P. Gautam, and P. K. Sharma, "Multiple quasi-steady states in a closed loop pulsating heat pipe," International Journal of Thermal Sciences 48, (3) (2009) 535-546.

[6] N. Zhao, H. Ma, and X. Pan, "Wavelet Analysis of Oscillating Motions in an Oscillating Heat Pipe," 2012.

[7] M. Mameli, S. Khandekar, and M. Marengo, "Are Dominant Oscillation Frequencies Always Present in Pulsating Heat Pipes?," Seventh International Symposium on Two-Phase Systems For Ground And Space Applications, Beijing, China, September 17-21, 2012, 2012.

[8] H. Peng, P. F. Pai, and H. Ma, "Nonlinear thermomechanical finite-element modeling, analysis and characterization of multi-turn oscillating heat pipes," International Journal of Heat and Mass Transfer 69, (2014) 424-437. 
[9] M. Mameli, M. Marengo, and S. Khandekar, "Local heat transfer measurement and thermofluid characterization of a pulsating heat pipe," International Journal of Thermal Sciences 75, (2014) 140-152.

[10] J. D. Fairley, S. M. Thompson, and D. Anderson, "Time-frequency analysis of flat-plate oscillating heat pipes," International Journal of Thermal Sciences 91, (2015) 113-124.

[11] V. K. Karthikeyan, K. Ramachandran, B. C. Pillai, and A. Brusly Solomon, "Understanding thermo-fluidic characteristics of a glass tube closed loop pulsating heat pipe: flow patterns and fluid oscillations," Heat and Mass Transfer/Waerme- und Stoffuebertragung 51, (12) (2015) $1669-1680$.

[12] G. Spinato, N. Borhani, and J. R. Thome, "Understanding the self-sustained oscillating twophase flow motion in a closed loop pulsating heat pipe," Energy 90, (2015) 889-899.

[13] J. G. Monroe, Z. S. Aspin, J. D. Fairley, and S. M. Thompson, "Analysis and comparison of internal and external temperature measurements of a tubular oscillating heat pipe," Experimental Thermal and Fluid Science 84, (2017) 165-178.

[14] R. G. Chi, W. S. Chung, and S. H. Rhi, "Thermal characteristics of an oscillating heat pipe cooling system for electric vehicle Li-ion batteries," Energies 11, (3) (2018).

[15] K. Ishii and K. Fumoto, "Temperature visualization and investigation inside evaporator of pulsating heat pipe using temperature-sensitive paint," Applied Thermal Engineering, (2019) $575-583$.

[16] A. Takawale, S. Abraham, A. Sielaff, P. S. Mahapatra, A. Pattamatta, and P. Stephan, "A comparative study of flow regimes and thermal performance between flat plate pulsating heat pipe and capillary tube pulsating heat pipe," Applied Thermal Engineering, (2019) 613-624.

[17] G. Buresti, G. Lombardi, and J. Bellazzini, "On the analysis of fluctuating velocity signals through methods based on the wavelet and Hilbert transforms," in Chaos, Solitons and Fractals 20, (1) (2004) 149-158.

[18] A. Mariotti, G. Buresti, G. Gaggini, and M. v. Salvetti, "Separation control and drag reduction for boat-tailed axisymmetric bodies through contoured transverse grooves," Journal of Fluid Mechanics 832, (2017) 514-549.

[19] M. Mameli et al., "Start-up in microgravity and local thermodynamic states of a hybrid loop thermosyphon/pulsating heat pipe," Applied Thermal Engineering, (2019).

[20] Catarsi, A., Fioriti, D., Mameli, M., Filippeschi, S., Di Marco, P., Accuracy analysis of direct infrared temperature measurements of two-phase confined flows, 16th International Heat Transfer Conference, Beijing, China, 10-15 August 2018.

[21] A. Mariotti, "Axisymmetric bodies with fixed and free separation: Base-pressure and nearwake fluctuations," Journal of Wind Engineering and Industrial Aerodynamics 176, (2018) $21-31$.

\section{Acknowledgments}

The present work is carried forward in the framework of the ESA MAP Project INWIP (4000115115/15/NL/PG and the EPSRC UK HyHP Project (EP/P013112/1). Thanks to the NOVESPACE team in Bordeaux, and especially to Ms. Alexandra Jacquemet for their ground and flight technical support. Thanks to Davide Fioriti, Roberto Manetti, Massimo Ciampalini, Franco Peticca, Davide Della Vista for their essential technical contribution and to Dr. Daniele Mangini, Marco Bernagozzi and Matteo Pozzoni for their support and the participation to the parabolic flight campaign. Special thanks to Dr. Balazs Toth and Dr. Daniele Mangini for their constant interest and support and to Prof. Guido Buresti for his valuable suggestions. Furthermore, the team would like to thank the TRP project, and the laboratory TEC-MMG at ESA/ESTEC for lending the MWIR camera. 